\title{
Alzheimer's Disease: potential benefits of curcumin
}

\author{
James W Anderson* \\ Emeritus, University of Kentucky and Grace E. Dender, Nursing Student, Belmont University, USA
}

Alzheimer's is a chronic neurodegenerative disease that usually starts slowly and gradually worsens over time. It is the cause of $60-$ $70 \%$ of cases of dementia among senior adults. The most common early symptom is difficulty in remembering recent events. As the disease advances, symptoms can include problems with language, disorientation, mood swings, loss of motivation, not managing selfcare, and behavioral issues [1]. As many as 5.7 million Americans were living with Alzheimer's disease in 2018 [2].

Treatment for Alzheimer's has been challenging because side effects of therapeutic agents; a genuinely new agent has not been approved since 2003 [3]. Recent studies suggest that curcumin may offer distinct benefits $[1,4-7]$.

\section{Health benefits of curcumin}

Turmeric spices have been used therapeutically since ancient times. The most active component in turmeric is curcumin, which constitutes $2-5 \%$ of the spice. Recent research has documented the antioxidant and anti-inflammatory activity of curcumin [8]. Despite its multineurotrophic properties, curcumin's use has been limited due to its poor absorption, rapid metabolism, and limited brain barrier permeability [9].

Curcumin has therapeutic efficacy against various human conditions and diseases including arthritis, cancer, cardiovascular diseases, Crohn's disease, degenerative joint disease, diabetes, hepatic disorders, inflammatory conditions, neurological diseases, oxidative stress, and skin disease [8-10]. These health benefits were documented using traditional curcumin products that were not prepared to optimize their absorption, bioavailability and efficacy.

In the last decade new curcumin formulations with improved bioavailability and minimal adverse effects have been developed. Meriva $^{\circ}$, Theracumin ${ }^{\circ}$ and Longvida ${ }^{\circ}$ were the first curcumin nanoparticle developed and tested. Allegri [11] documented that Meriva (110 mg bid) was well tolerated and reduced eye discomfort over a 12-month period of follow-up. Appendino [12] evaluated the clinical effects of Meriva (100 mg bid) for patients with diabetic microangiography; compared to control subjects, Meriva-treated patients showed clinical improvement and tolerated the Meriva well. Belcaro \& Rosaria [13] reported that patients with osteoarthritis had significant improvement in clinical and biochemical endpoints over an eight-month period while receiving Meriva $100 \mathrm{mg}$ bid with excellent tolerability.

Sasaki [14] demonstrated the bioavailability and tolerability of Theracumin ${ }^{\circ}$. Small reported that Theracumin ${ }^{\circledR}$ (with curcumin doses of $180 \mathrm{mg} / \mathrm{d}$ ) improved memory, attention and mood in non-demented adults. Ullah [8] predicted that curcumin would prevent and slow progression of neuroinflammatory brain disease in human adults.
Cox [4] utilized Longvida $a^{\oplus}$ optimized curcumin in a randomized, double-blind, controlled study of 60 healthy adults aged 60 to 85 . With a dose of $80 \mathrm{mg}$ curcumin daily, alertness and contentedness were significantly improved with good tolerability. Scholey [7] reported that administration of Longvida ${ }^{\circ}$ during a 12 -week randomized, doubleblind, placebo-controlled study improved neurocognitive function and mood in healthy older people.

\section{Bioavailable curcumin effects on memory in humans}

While long-term, controlled clinical trials examining the effects of bioavailable curcumin for patients with Alzheimer's disease have not been reported yet, clinical studies $[4,6,7]$ are very encouraging. In addition, Rainey-Smith [5] examined the effects of Biocurcurmax ${ }^{\mathrm{m}}$ on mental function of older adults. This product also had enhanced bioavailability and was associated with a smaller decline in mental function.

Because the efficacy of these new bioavailable curcumins experts $[3,15]$ are beginning to recommend their use for persons with Alzheimer's disease. Because adult senior individuals may also have serum glucose or lipid challenges, or gastrointestinal problems, cardiac challenges or other conditions that curcumin may benefit [9], curcumin may have a range of benefits for persons with Alzheimer's disease. Reported side effects from the new bioavailable curcumins have been minimal [4-7,10-12].

\section{Recommended Bioavailable Curcumin Products, Doses and Initial Doses}

Longvida ${ }^{\circledR}$ Optimized Curcumin: 500 mg curcumin capsules;

Meriva $^{\circledR}$ SF: $500 \mathrm{mg}$ curcumin capsules;

Theracumin HP: $180 \mathrm{mg}$ curcumin capsules (usual dose is 2 capsules);

TrueCurcumin $^{\mathrm{TM}} \mathbf{B C M}^{-95}{ }^{\circledR}: 500 \mathrm{mg}$ curcumin capsules. The usual initial recommendation is one dose 1 or 2 hours after lunch or dinner for one or two weeks and then one dose after each of these two meals.

\section{Conclusions}

Based on the available of these bioavailable curcumins and the clinical studies that have emerged in the last decade, we feel that care providers should consider use of these new curcumins in patients with Alzheimer's disease. Because there are over 80 different curcumin products currently available, care providers and consumers may not

${ }^{\star}$ Correspondence to: James W Anderson, MD, Professor of Medicine, Emeritus, University of Kentucky, 4343 Lebanon Pike, Appt 1004, Hermitage, TN 37076, USA, E-mail: jwandersmd@aol.com

Received: August 30, 2019; Accepted: September 17, 2019; Published: September 20, 2019 
be able assess which curcumin product they should recommend or choose. Thus, we have outlined several of the bioavailable products and potential initial doses.

\section{References}

1. Goozee KG, Shah TH, Sohrabi HR, Rainey-Smith SR, Brown B, et al. (2016) Examining the potential clinical value of curcumin in the prevention and diagnosis of Alzheimer's disease. Brit J Nutr 115: 449-465.

2. Park A (2018) New hope for Alzheimer's. Time Magazine 20: 40-46.

3. Bredesen DE (2017) The End of Alzheimer's. Avery; Penguin Random House LLC, New York.

4. Cox KH, Pipingas A, Scholey AB (2015) Investigation of the effects of solid lipid curcumin on cognition and mood in a healthy older population. $J$ Psychopharmacol 29: 642-651. [Crossref]

5. Rainey-Smith SR, Brown BM, Sohraba HR, Shah T, Goozee KG, et al. (2016) Curcumin and cognition: a randomized, placebo-controlled, double-blind study of community-dwelling older adults. Brit J Nutri 115: 2106-2113.

6. Small GW, Siiarth P, Zhaoping L, Miller KJ, Ercola L, et al. (2018) Memory and Brain Amyloid and Tau Effects of a Bioavailable form of Curcumin in Non-Demented Adults: A Double-Blind, Placebo-Controlled 18-Month Trial. Am J Geriatr Psych 26: 266-277.

7. Scholey A, Cox K, Pipingas A, White (2019) A highly bioavailable curcumin extract improves neurocognitive function and mood in the healthy older people: a 12-week randomized, double-blind, placebo-controlled trial (OR32-05-19). Curr Dev Nutr 3: 26-34.
8. Ullah F, Liang A, Rangel A, Gyengesi E, Niedermayer G, et al. (2017) High bioavailability curcumin: an anti-inflammatory and neuro-supportive bioactive nutrient for neurodegenerative diseases characterized by chronic neuroinflammation. Arch Toxicol 91: 1623-1634.

9. Anand P, Kunnumakkara AB, Newman RA, Aggarwal BB (2007) Bioavailability of curcumin: problems and promises. Mol Pharm 4: 807-818. [Crossref]

10. Shin Y, Suk MH, Jang HS, Joy HJ (2017) Short-term effects of Theracurmin dose and exercise type on pain, walking ability, and muscle function in patients with knee osteoarthritis. J Exerc. Rehabil 13: 684-692.

11. Allegri P, Mastromarino A, Neri P (2010) Management of chronic anterior uveitis relapses: efficacy of oral phospholipidic curcumin treatment. Long-term follow-up. Clin Ophthal 4: 1201-1206.

12. Appendino G, Belcaro G, Cornelli U, Luzzi R, Togni S, et al. (2010) Potential role of curcumin phytosome (Meriva) in controlling the evolution of diabetic microangiopathy. A pilot study. Panminerva Med 53(3 Suppl. 1): 43-49.

13. Belcaro G, Cesarone R, Dugal, M, Pellegrini L, Ledda A, et al. (2010) Efficacy and

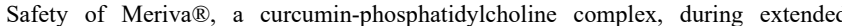
administration in osteoarthritis patients. Altern Med Rev 15: 337-344.

14. Sasaki H, Sunagawa Y, Takahashi K, Imaizumi A, Fukuda H, et al. (2011) Innovative preparation of curcumin for improved oral bioavailability. Biol Pharm Bull 34: 660665. [Crossref]

15. West, F (2018) Alzheimer's and pain results already forthcoming with turmeric forte. Health Alert Newsletter 35: 10.

Copyright: $\odot 2019$ Anderson JW. This is an open-access article distributed under the terms of the Creative Commons Attribution License, which permits unrestricted use, distribution, and reproduction in any medium, provided the original author and source are credited. 